\title{
EKSPLORASI ETNOMATEMATIKA TERHADAP TRANSFORMASI GEOMETRI PADA BATIK MALEFO
}

\author{
Ariestha Widyastuty Bustan ${ }^{1 *}$, Munazat Salmin ${ }^{2}$, Taufan Talib ${ }^{3}$ \\ ${ }^{1}$ Prodi Matematika Fakultas Matematika dan Ilmu Pengetahuan Alam, Universitas Pasifik Morotai \\ Jalan Siswa Darame, Morotai Selatan, Pulau Morotai, Maluku Utara, Indonesia \\ ${ }^{2}$ Prodi Teknik Informatika Fakultas Teknik, Universitas Khairun Ternate \\ Jalan Jati, Kampus III Unkhair, Ternate Selatan, Ternate, Indonesia \\ ${ }^{3}$ Prodi Pendidikan Matematika Fakultas Keguruan dan Ilmu Pendidikan, Universitas Pattimura \\ Jalan Ir. M. Putuhena, Kampus Unpatti, Poka, Ambon, Indonesia \\ e-mail: ${ }^{1}$ ariesthawidyastutybustan@gmail.com; \\ Submitted: November 29, 2021 \\ Revised: January 7, 2022 \\ Accepted: January 20, 2022 \\ corresponding author*
}

\begin{abstract}
Abstrak
Konsep matematika yang bersiftat abstrak mengharuskan adanya pemanfaatan objek sekitar lingkungan siswa agar membuat konsep matematika lebih konkrit. Salah satu objek sekitar yang dapat digunakan adalah objek budaya. Secara khusus pendekatan yang mengaitkan matematika dengan kebudayaan adalah pendekatan etnomatematika. Penelitian ini bertujuan untuk mengeksplorasi etnomatematika terhadap materi transformasi geometri pada batik malefo yang merupakan batik khas Kota Ternate. Jenis penelitian ini adalah penelitian kualitatif dengan pendekatan etnografi. Pengumpulan data dilakukan dengan cara studi kepustakaan, metode pengamatan, metode wawancara, dan metode dokumentasi. Subjek dalam penelitian ini adalah pemilik galeri batik malefo. Data yang diperoleh dalam penelitian ini berasal dari observasi langsung, hasil wawancara dengan subjek penelitian dan hasil dokumentasi. Hasil penelitian ditemukan bahwa motif yang digunakan pada batik malefo dapat menjadi contoh konkrit dari jenis-jenis transformasi geometri, yaitu pada transformasi geometri jenis translasi pada motif batik rangkaian bunga cengkeh dan parang, jenis refleksi pada motif batik bunga cengkeh pala salawaku parang dan bunga kelapa, jenis dilatasi pada motif batik dodia, serta jenis rotasi pada motif batik cengkeh dan bunga cengkeh. Contoh yang direpresentasikan pada batik malefo selanjutnya dapat direkomendasikan sebagai alternatif media pembelajaran agar siswa dapat lebih memahami materi transformasi geometri.
\end{abstract}

Kata Kunci: batik malefo, etnomatematika, geomerti transformasi

\section{ETHNOMATHEMATICS EXPLORATION OF GEOMETRY TRANSFORMATION IN MALEFO BATIK}

\begin{abstract}
Abstract mathematical concepts require using objects around the student's environment to make mathematical concepts more concrete. One of the objects around that can be used is a cultural object. In particular, the approach that links mathematics with culture is the ethnomathematical approach. This study explores the ethnomathematics of the geometric transformation material on malefo batik, a typical batik of Ternate City. This type of research is qualitative research with an ethnographic approach. Data was collected using literature study, observation, interview, and documentation methods. The subject of this research is the owner of the Malefo batik gallery. The data obtained in this study came from direct observation, interviews with research subjects, and document results. The results of the study found that the motifs used in malefo batik can be a concrete example of the types of geometric transformations, namely the translational type of geometric transformation on the clove and machete flower arrangement batik motifs, the type of reflection on the clove flower motif, nutmeg, salawaku, parang and coconut flowers, the type of dilatation in the dodia batik motif, as well as the rotation type in the clove and clove flower motifs. The examples represented in Malefo batik can then be recommended as an alternative learning media to understand the material of geometric transformation better.
\end{abstract}

Keywords: malefo batik, etnomathematics, geometry transformation 


\section{Pendahuluan}

Pendidikan adalah salah satu sarana yang bisa memenuhi proses belajar mengajar pada setiap manusia. Melalui pendidikan setiap manusia, khususnya para siswa dapat memperoleh berbagai macam pembelajaran yang bisa diaplikasikan ke dalam kehidupan sehari-hari agar kehidupan menjadi lebih mudah dan bermakna. Sebagai salah satu bagian dari satuan pendidikan, mutu suatu sekolah memiliki peranan yang sangat penting dalam memberikan pendidikan yang baik bagi para siswa. Banyak faktor yang mendukung baik atau tidaknya mutu suatu sekolah itu sendiri. Salah satunya adalah metode dan pendekatan pembelajaran yang diterapkan.

Setiap mata pelajaran atau materi yang diajarkan di sekolah memiliki karakteristik dan tingkat pemahaman yang berbeda-beda. Sehingga dalam penerapannya setiap guru tentunya harus menyesuaikan pendekatan pembelajaran yang digunakan. Misalnya dalam pembelajaran matematika. Lutvaidah dalam penelitiannya mengatakan bahwa metode serta pendekatan pembelajaran memiliki pengaruh yang sangat signifikan terhadap penguasaaan konsep matematika siswa (Lutvaidah, 2016). Namun tidak masalah selanjutnya yang muncul adalah tidak semua metode ataupun pendekatan memiliki bisa cocok dengan semua materi yang diajarkan dalam matematika. Sehingga banyak penelitian yang mengukur kecocokan pendekatan pembelajaran dengan penguasaaan konsep matematika siswa.

Salah satu pendekatan pembelajaran yang gencar diterapkan pada pembelajaran matematika adalah pembelajaran dengan pendekatan kontekstual. Dibandingkan dengan pembelajaran konvensional, pembelajaran dengan pendekatan kontekstual lebih dikaitkan dengan kehidupan nyata atau masalah yang disimulasikan, selain itu siswa lebih aktif terlibat dalam proses pembelajaran (Kadir, 2013). Disamping itu pembelajaran dengan pendekatan kontekstual juga mampu meningkatkan keaktifan dan koneksi matematika siswa (Yanti, Fauziyah, \& Friansah, 2017).

Ada banyak cara dalam upaya realisasi pembelajaran dengan pendekatan kontekstual. Salah satunya adalah dengan mengaitkan pendekatan kontekstual dengan kearifan lokal atau budaya tempat lingkungan siswa berada. Ramdani dalam penelitiannya telah memberikan wawasan terkait model pembelajaran kontekstual yang berbasis kearifan lokal (Ramdani, 2018). Secara khusus pendekatan yang mengaitkan matematika dengan kebudayaan adalah pendekatan etnomatematika.

Beberapa penelitian yang berkaitan pendekatan etnomatematika diantaranya dalam penelitiannya konsep matematika yang diberikan di sekolah dapat diintegrasikan dengan pendekatan etnomatematika dan bisa memberikan gambaran bahwa dalam sebuah kerajinan terkandung konsepkonsep matematika. Pembelajaran matematika yang melalui objek etnomatematika bisa membuat matematika lebih aplikatif serta dapat membuat siswa lebih memahami matematika yang bersifat abstrak dengan menggunakan objek etnomatematika yang konkrit (Hardiarti, 2017). Dalam hal ini Hardianti melihat representasi bangun datar segiempat pada Candi Muaro Jambi. Selain objek etnomatematika dalam kerajinan dan candi, Huda dalam penelitianya juga menampilkan representasi objek matematika pada jajanan pasar di Daerah Istimewa Yogyakarta (Huda, 2018).

Dari beberapa literatur di atas, ditemukan bahwa berbagai unsur budaya dapat merepresentasikan objek matematika sebagai alternatif media pembelajaran pada materi matematika. Konsep matematika yang abstrak, mengharuskan adanya pemanfaatan objek sekitar agar membuat konsep matematika lebih konkrit. Hal tersebut tentunya juga berlaku pada materi geometri transformasi. Salah satu cara yang dapat dilakukan agar koneksi matematis siswa meningkat saat menerima materi geometri transformasi adalah dengan memberikan kesempatan pada siswa untuk mengaitkan materi matematika dengan apa yang didapatinya dalam kehidupan sehari-hari dan tentunya dalam contoh yang lebih konkrit (Lydiati, 2020).

Hal tersebut yang mendasari penelitianpenelitian terbaru yang berkaitan dengan pembelajaran kontekstual untuk lebih menekankan pada upaya mengeksplorasi objek sekitar yang dapat merepresentasikan materi-materi matematika khususnya materi transformasi geometri. Konsep yang berkaitan dengan materi transformasi geometri dapat diperoleh dari motifmotif yang direpresentasikan pada kain besurek Bengkulu (Yanti \& Haji, 2019). Selain pada kain basurek khas Bengkulu, konsep matematika juga ditemukan pada pakaian Suku Dayak Kenyah (Edi, 2021). Tidak hanya pada kerajinan kain, konsepkonsep matematika juga dapat ditemukan pada rumah adat di banyuwangi (Hariastuti, 2018).

Melihat begitu beragam pemanfaatan objek budaya sebagai objek yang merepresentasi konsep matematika, sehingga peneliti tertarik untuk melakukan eksplorasi terhadap objek sekitar yang 
dapat merepresentasikan konsep transformasi geometri menjadi lebih konkrit. Disisi lain, Ternate sebagai salah satu budaya memiliki objek budaya yang sangat melimpah, baik dari segi kerajinan, tempat peninggalan bersejarah dan lain sebagainya. Meskipun demikian, sangat sedikit penelitian yang mengeksplorasi konsep matematika pada objek budaya yang ada di kota Ternate khususnya pada kerajinan batik khas Ternate, yaitu batik malefo.

Berdasarkan observasi awal, beberapa unsur pada motif batik malefo yang dibuat dalam bentuk penggambaran berulang yang merepresentasikan contoh jenis transformasi geometri translasi. Motif batik malefo memiliki motif yang beragam dan menunjukkan ciri khas Kota Ternate. Batik malefo dibuat dengan pola yang simetris dengan ukuran dan penempatan pola yang beraturan. Oleh karena itu, dalam penelitian ini akan dieksplorasi konsep etnomatematika dalam motif batik malefo untuk melihat representasi jenis-jenis transformasi geometri lainnya pada motif batik malefo tentunya.

\section{Metode Penelitian}

Penelitian ini dilaksanakan di Kelurahan Tubo, Kecamatan Kota Ternate Utara, Kota Ternate. Jenis penelitian yang digunakan adalah jenis penelitian kualitatif dengan pendekatan etnografi. Melalui pendekatan etnografi, teknik pengumpulan data yang dilakukan adalah dengan cara studi kepustakaan, dan selanjutnya diperkuat dengan pengumpulan data melalui metode pengamatan, metode wawancara, dan metode dokumentasi. Subjek dalam penelitian ini adalah orang yang bekerja di galeri batik malefo. Untuk mengecek keabsahan data yang diperoleh digunakan Teknik triangulasi data.

Selain dari hasil pengamatan langsung, sebagian besar data untuk gambar motif motif batik dilansir dari web resmi batik malefo itu sendiri yaitu dari ("https://batikmalefo.com/," n.d.). Berikut ini adalah alur dari tahapan penelitian yang dilakukan.

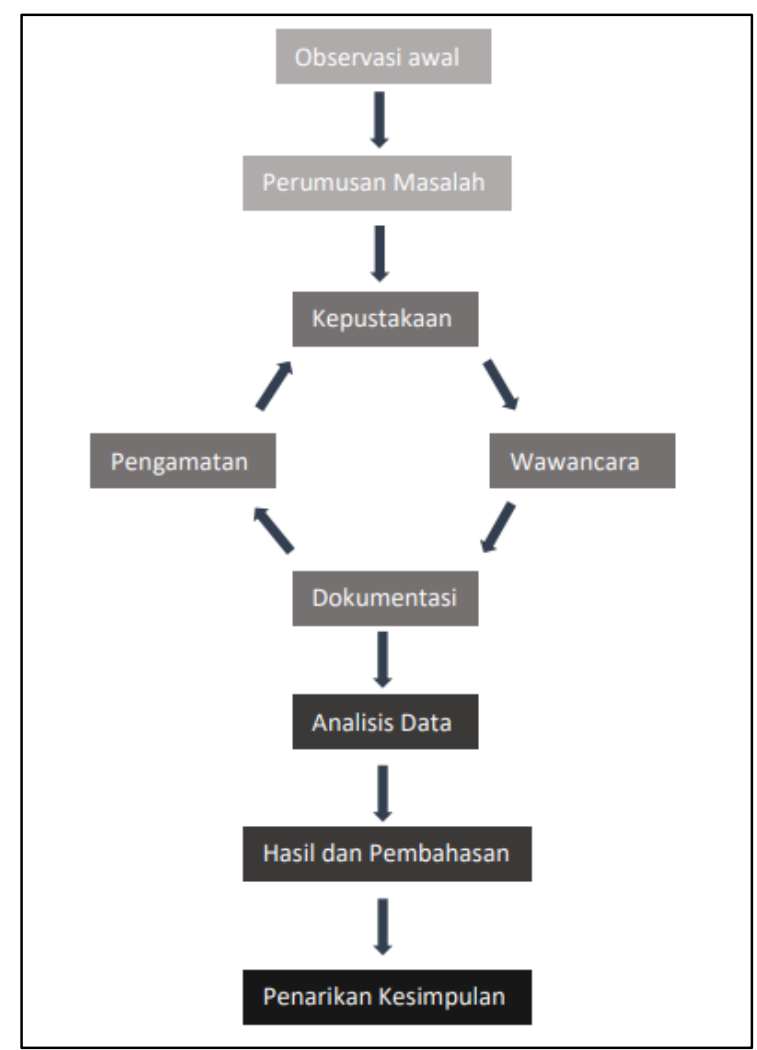

Gambar 1. Alur Penelitian

\section{Hasil dan Pembahasan}

Batik malefo merupakan batik khas ternate yang merupakan pencetus batik di Kota Ternate sejak tahun 2015. Galeri batik malefo berada di kelurahan Tubo, Kecamatan Kota Ternate Utara. Semua motif yang digunakan pada batik malefo merepresentasikan budaya dan kearifan lokal dari kota Ternate itu sendiri.

Beberapa motif tersebut diantaranya motif rangkaian bunga cengkeh, salawaku parang, bunga cengkeh dan parang, bunga cengkeh pala dan salawaku parang, rangkaian bunga kelapa, motif dodia, dan motif pala. Selain dijual sebagai kain batik, batik malefo juga dijadikan sebagai produk lainnya seperti kemeja pria, baju wanita, baju sekolah, topi dan aksesoris lainnya.

Mata pelajaran transformasi geometri merupakan salah mata pelajaran matematika untuk Sekolah Menengah Atas kelas XI. Transformasi geometri adalah perubahan pada sebuah bidang geometri yang berkaitan dengan posisi, besar (ukuran) dan bentuknya sendiri. Transformasi geometri sendiri terbagi menjadi empat jenis yaitu translasi, refleksi, dilatasi, dan rotasi. 


\subsection{Translasi}

Translasi adalah pergeseran maupun pemindahan semua titik pada bidang geometri dengan memperhatikan arah dan jarak yang sama.

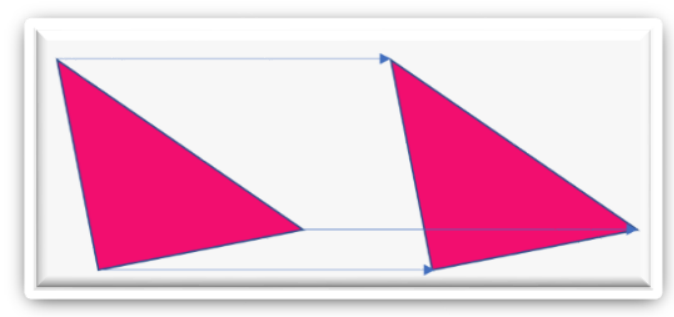

Gambar 2. Translasi

Pada batik malefo beberapa motif yang dapat digunakan sebagai contoh dari aplikasi translasi adalah sebagai berikut.

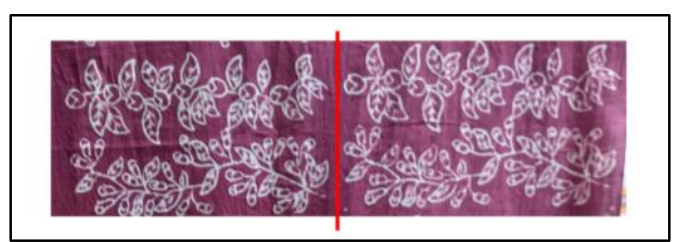

Gambar 3. Motif batik rangkaian bunga cengkeh

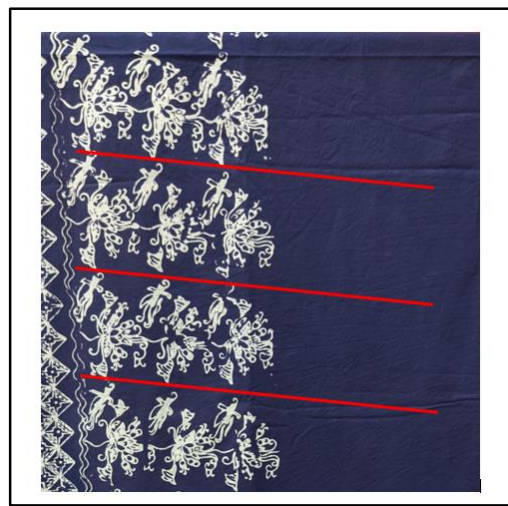

Gambar 4. Motif batik rangkaian bunga cengkeh dan parang

Pada Gambar 3, rangkaian bunga cengkeh di sisi kiri dapat dipandang sebagai titik asal atau posisi awal dan kemudian digeser ke kanan untuk menghasilkan bentuk rangkaian bunga cengkeh yang sama. Dengan kata lain menduplikasi rangkaian bunga cengkeh tersebut sebanyak yang diinginkan oleh pengrajin batik kain malefo. Sama halnya dengan Gambar 3, pada Gambar 4 adalah gambar motif batik rangkaian bunga cengkeh dan parang juga digambarkan pada batik dengan menduplikasi gambar motif yang sama dan digeser sejauh jarak yang diinginkan oleh pengrajin batik.

Translasi atau pergeseran bisa dilihat dalam sumbu $x$ serta sumbu $y$. Proses pergeseran sejauh $a$ yang sejajar dengan sumbu $x$ (digeser ke kanan untuk $a>0$, ke kiri untuk $a<0$ ) dan mengalami pergeseran sejauh $b$ sejajar sumbu $y$ (digeser ke atas untuk $b>0$, ke bawah untuk $b<0$ ) didefinisikan oleh:

$$
T=\left(\begin{array}{l}
a \\
b
\end{array}\right)
$$

Dengan $a$ dan $b$ merupakan komponen dari translasi. Berikut ini adalah bentuk dari translasi $\operatorname{sejauh} \frac{a}{b}$ :

Tabel 1. Translasi pada motif batik malefo

\begin{tabular}{ccc}
\hline $\boldsymbol{A}(\boldsymbol{x}, \boldsymbol{y}) \quad \boldsymbol{A}^{\prime}(\boldsymbol{x}+\boldsymbol{a}, \boldsymbol{y}+\boldsymbol{b}) \quad$ Pergeseran \\
\hline Motif batik rangkaian bunga cengkeh
\end{tabular}

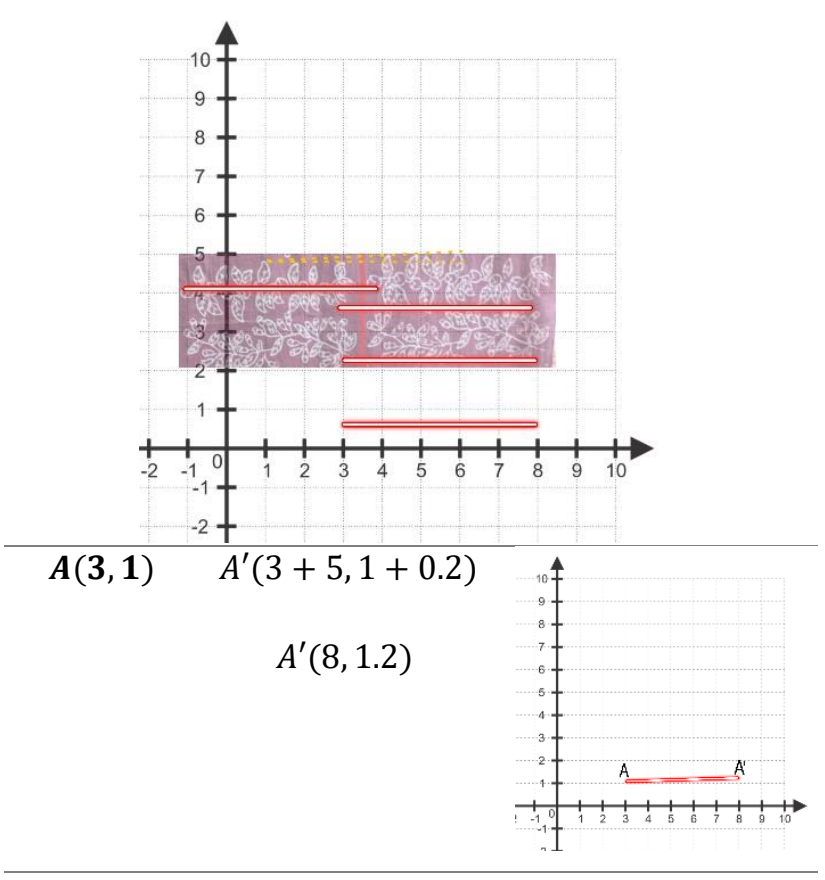

Motif batik rangkaian bunga cengkeh dan parang

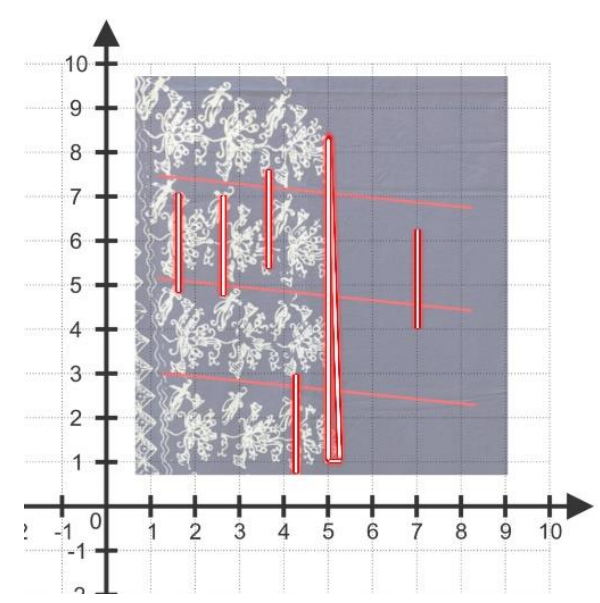

$\boldsymbol{A}(\mathbf{2}, \mathbf{1}) \quad A^{\prime}(2+(-0.3), 1$ $+2.25)$

$A^{\prime}(1.7,3.25)$

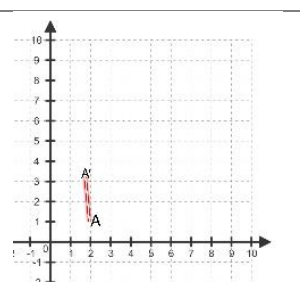


Pada tabel 1. diperoleh motif batik rangkaian bunga cengkeh, gambar bunga cengkeh mengalami pergeseran atau translasi sejauh 5.2 . Sedangkan pada motif rangkaian bunga cengkeh dan parang, bentuk atau gambar bunga cengkeh mengalami pergeseran sejauh $\frac{-0.3}{2.25}$

\subsection{Refleksi}

Refleksi merupakan jenis transformasi geometri di mana pergeseran semua titik di bidang geometri menuju ke arah garis (cermin) dengan jarak yang sama serta dua kali jarak dari titik ke cermin.

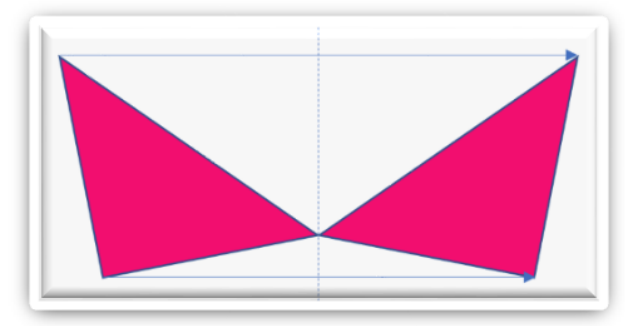

Gambar 5. Refleksi

Pada batif malefo, motif yang dapat menggambarkan bentuk refleksi adalah sebagai berikut.

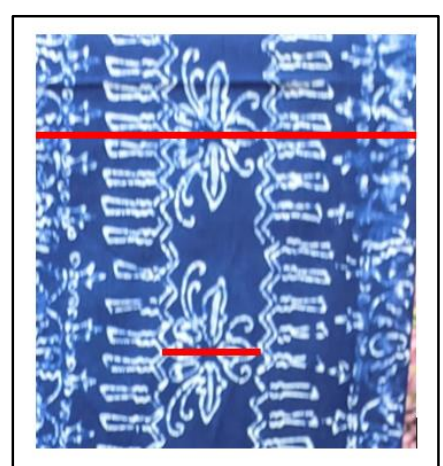

Gambar 6. Motif bunga cengkeh pala salawaku parang

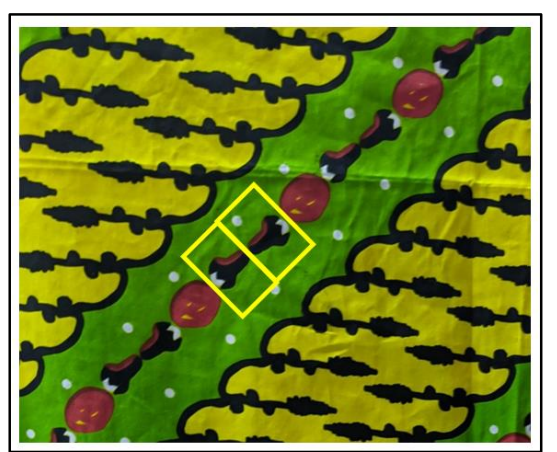

Gambar 7. Motif rangkaian bunga kelapa

Terdapat dua ciri utama suatu objek dikatakan mengalami refleksi yaitu jarak titik ke cermin sama dengan jarak dari bayangn titik ke cermin. Selain itu geometri yang direfleksikan atau dicerminkan tentunya berhadapan dengan petanya.
Motif batik malefo pada Gambar 6, menggambarkan pencerminan dari beberapa bentuk motif sekaligus, yakni pada gambar bunga cengkeh dan salawaku parang. Sedangkan untuk motif pada Gambar 7 translasi diterapkan pada gambar bunga kelapa. Berikut ini adalah tabel yang akan menjabarkan secara terperinci bentuk refleksi dari motif-motif tersebut.

Tabel 2. Bentuk refleksi pada batik malefo

$\boldsymbol{A}(\boldsymbol{x}, \boldsymbol{y}) \quad \boldsymbol{A}^{\prime}\left(\boldsymbol{x}^{\prime}, \boldsymbol{y}^{\prime}\right) \quad$ Pencerminan

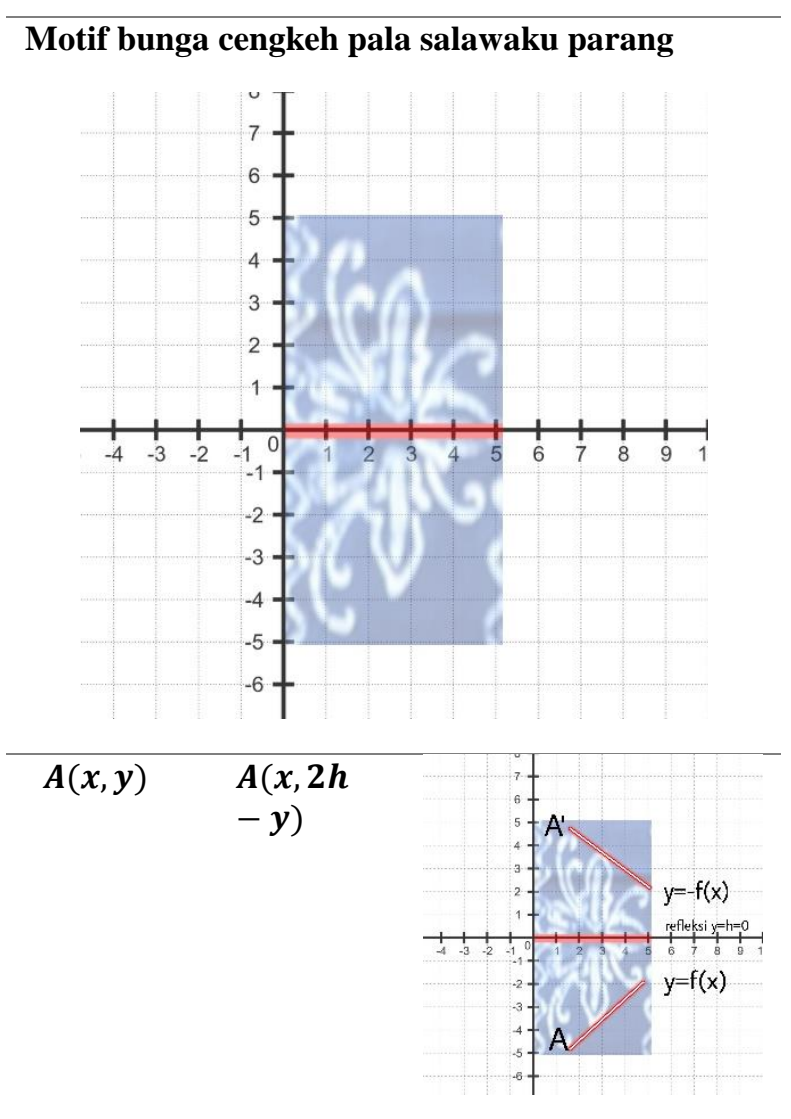

Motif rangkaian bunga kelapa

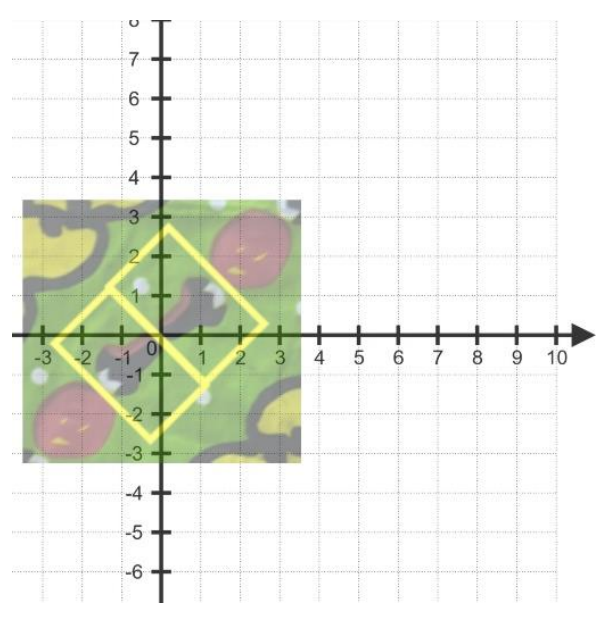




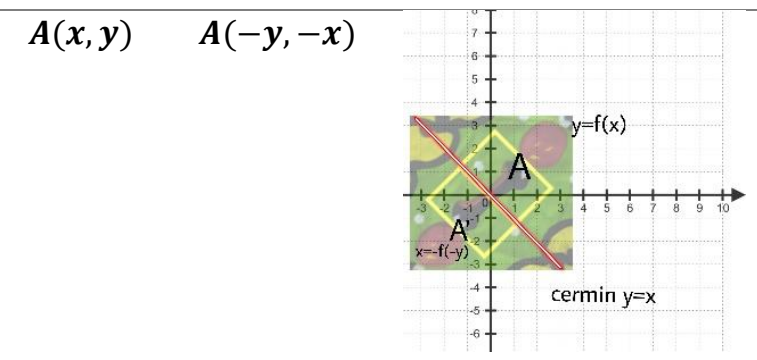

Tabel 2. diperoleh motif bunga cengkeh pala salawaku parang merepresentasikan transformasi geometri jenis refleksi dengan bentuk pencerminan yang terjadi adalah terhadap sumbu $x$. Sedangkan untuk motif rangkaian bunga kelapa dicerminkan terhadap sumbu $y=x$

\subsection{Dilatasi}

Dilatasi adalah transformasi geometri yang berupa perbesaran atau perkecilan bangunan geometri.

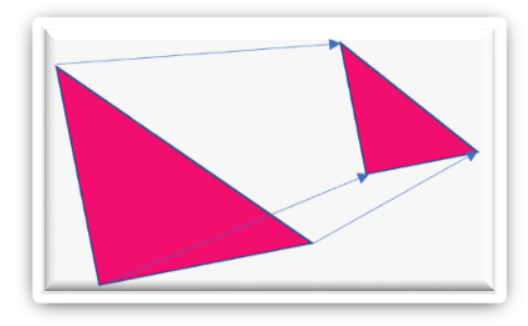

Gambar 8. Dilatasi

Berikut ini contoh motif pada batik malefo yang menggambarkan bentuk transformasi geometri jenis dilatasi.

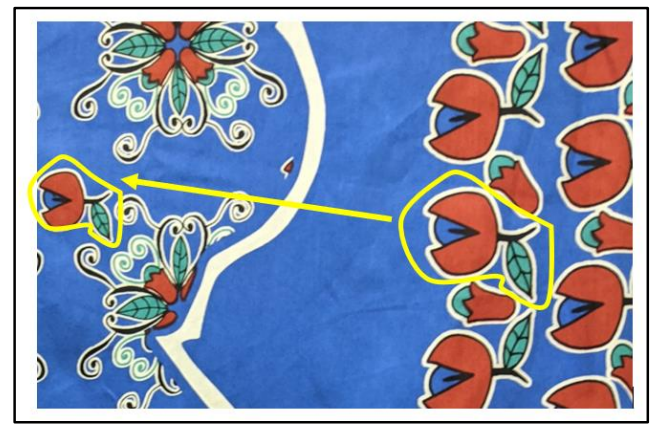

Gambar 9. Motif batik dodia

Pada motif batik dodia terlihat gambar buah pala diduplikasikan dengan ukuran yang sama serta ukuran yang berbeda. Ukuran yang berbeda inilah yang dikatakan sebagai bentuk tranformasi geometri jenis dilatasi.

Istilah penting dalam konsep transformasi geometri adalah faktor dilatasi. Faktor dilatasi adalah faktor perkalian dari suatu bangun geometri yang mengalami dilatasi. Faktor dilatasi menggambarkan besar dari hasil dilatasi terhadap bangun geometrinya serta dinotasikan sebagai $k$.
Di mana untuk nilai $k>1$ atau nilai $k<-1$ menyatakan hasil dari dilatasi yang lebih besar dari geometrinya. Sedangkan untuk faktor dilatasi dengan nilai $-1<k<1$ menyatakan hasil yang lebih kecil. Berkaitan dengan tanda positif dan negatif, tanda positif menyatakan jika geometri dan hasil dilatasi berdampingan di salah satu sisi titik dilatasi. Sebaliknya tanda negatif menyatakan geometri dan hasil dilatasi saling terbalik dan berlainan sisi di titik dilatasi.

Untuk notasi dilatasi dapat dinyatakan dengan:

$$
(D, k)
$$

Dengan D adalah titik dilatasi dan $k$ adalah factor dilatasi. Berikut ini adalah faktor dilatasi dan bentuk dilatasi dari motif dodia pada batik malefo.

Tabel 3. Faktor dilatasi dan bentuk dilatasi motif dodia

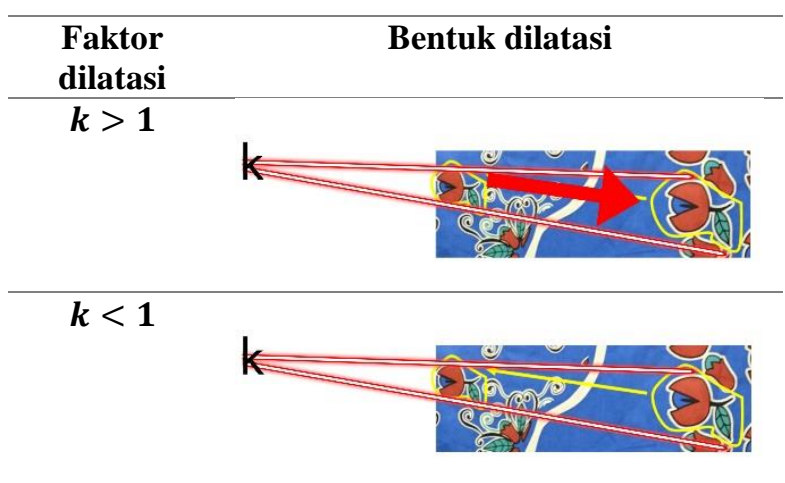

Tabel 3 diperoleh faktor dilatasi dari motif dodia bias lebih besar dari 1 atau kurang dari 1 tergantung dari perspektif gambar bunga pala yang mana yang lebih dahulu digambar pada kain batik motif dodia.

\subsection{Rotasi}

Rotasi adalah transformasi geometri yang merupakan pemindahan atau pergeseran semua titik di bidang geometri yang berada di sepanjang busur lingkaran dengan titik rotasi berupa titik pusat lingkaran.

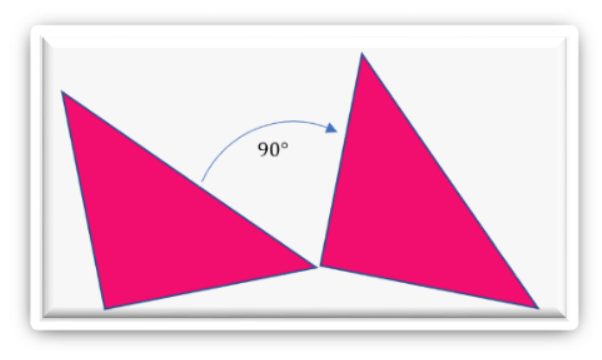

Gambar 10. Rotasi

Rotasi dapat dinyatakan sebagai rotasi positif jika berlawanan dengan arah jarum jam, sedangkan rotasi dikatakan sebagai rotasi negatif 
jika searah dengan arah jarum jam. Gambar 11 dan Gambar 12 adalah contoh motif pada batik yang dapat merepresentasikan bentuk transformasi geometri jenis rotasi.

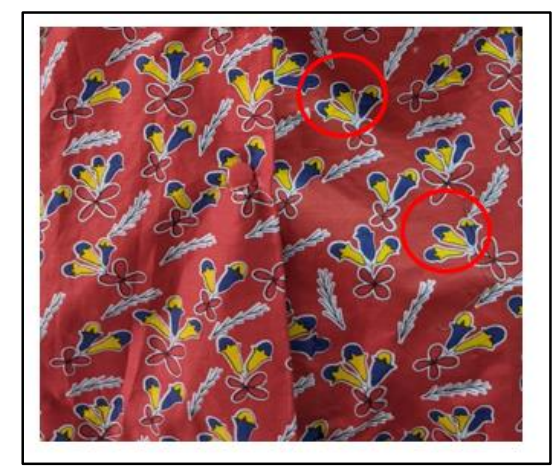

Gambar 11. Motif batik cengkeh

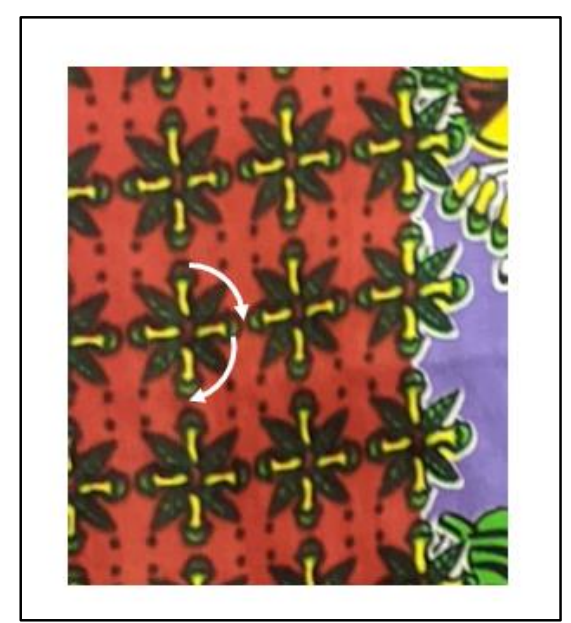

Gambar 12. Motif batik bunga cengkeh

Motif batik cengkeh merepresentasikan transformasi geometri jenis rotasi dengan menduplikasi gambar secara acak dan tempat yang tidak beraturan. Sedangkan pada motif bunga cengkeh, cengkeh dirotasikan secara teratur karena sekaligus sekumpulan cengkeh yang dirotasikan mengalami dilatasi. Berikut ini akan ditampilkan bentuk rotasi dari bentuk-bentuk gambar yang ada pada motif batik malefo dari sisi bentuk rotasi yang berbeda.

Tabel 4. Bentuk rotasi pada batik malefo

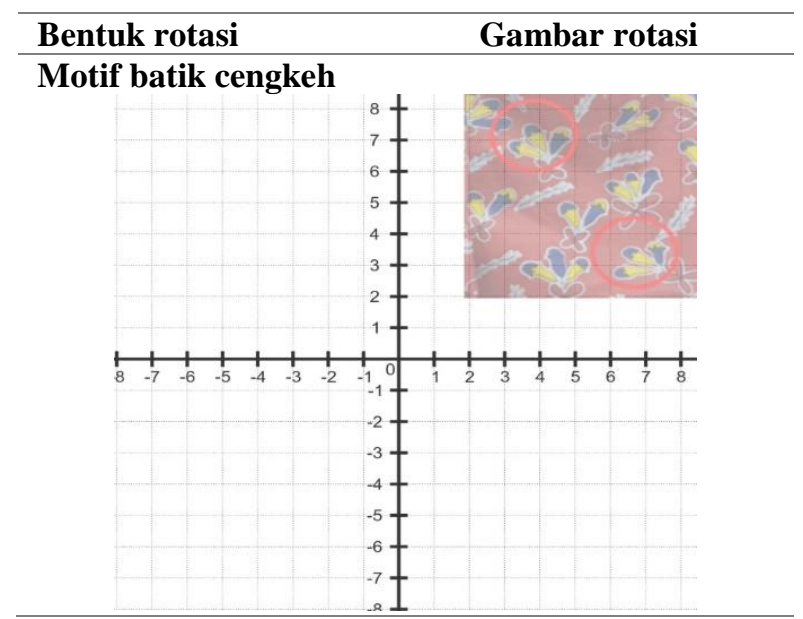

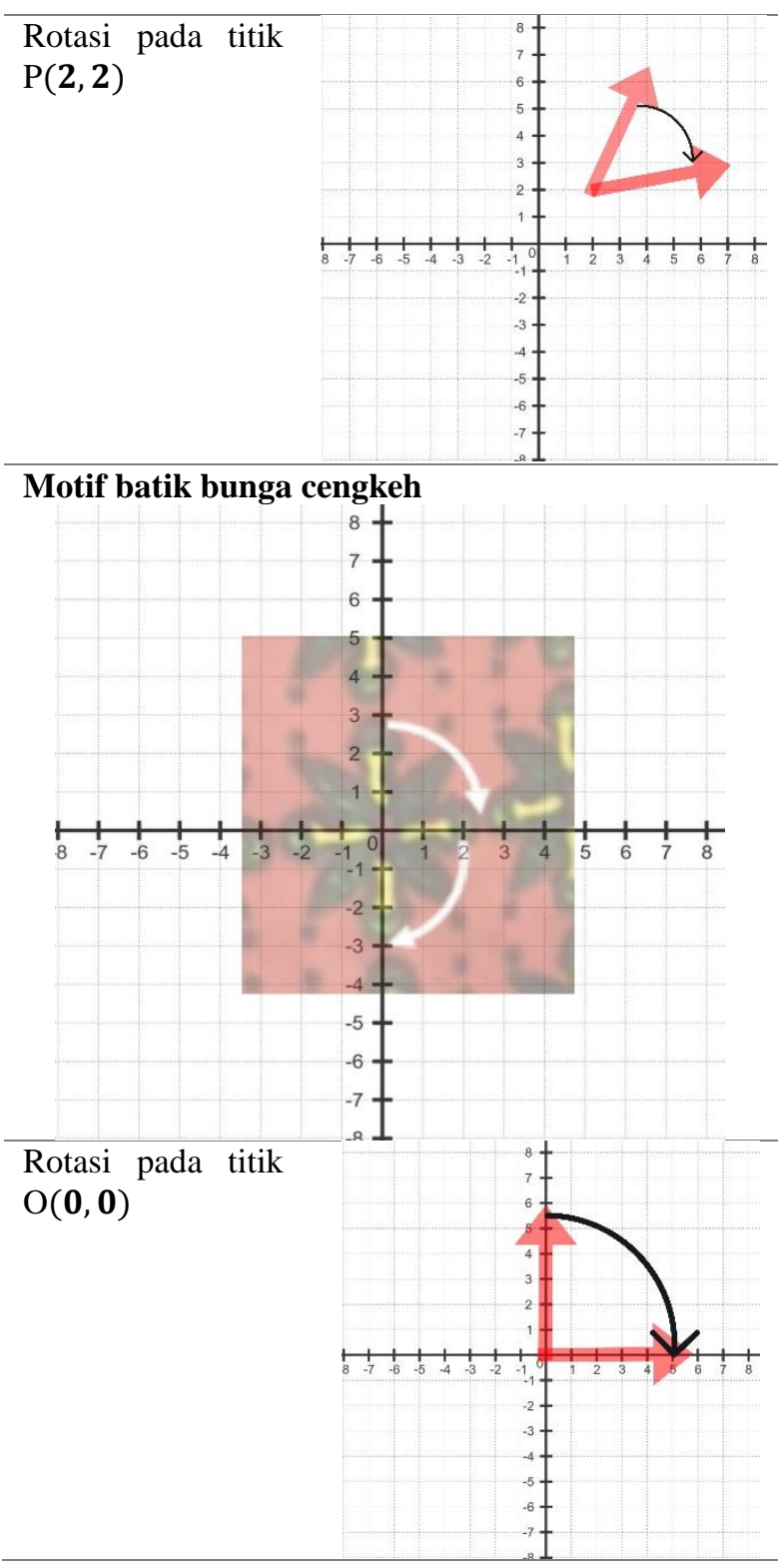

Tabel 4 diperoleh dua bentuk rotasi pada motif batik malefo yaitu pada titik rotasi $P(a, b)$ atau $P(2,2)$ dan pada titik rotasi titik pusat $O(0,0)$. Pada perspektif yang diberikan pada tabel tersebut diketahui jenis rotasi pada kedua motif batik yang dicontohkan adalah jenis rotasi negatif karena searah jarum jam

\section{Kesimpulan}

Berdasarkan hasil dan pembahasan penelitian yang diperoleh maka dapat disimpulkan bahwa ditemukan unsur-unsur gambar motif batik yang dapat dijadikan sebagai objek matematika. Objek matematika tersebut merepresentasikan contoh dari jenis-jenis transformasi geometri, yaitu transformasi geometri jenis translasi, refleksi, dilatasi dan rotasi.

Motif-motif batik yang merepresentasikan transformasi geometri tersebut diantaranya pada 
transformasi geometri jenis translasi pada motif batik rangkaian bunga cengkeh dan parang, jenis refleksi pada motif batik bunga cengkeh pala salawaku parang dan bunga kelapa, jenis dilatasi pada motif batik dodia, serta jenis rotasi pada motif batik cengkeh dan bunga cengkeh. Contoh yang direpresentasikan pada batik malefo selanjutnya dapat direkomendasikan sebagai alternatif media pembelajaran agar siswa dapat lebih memahami materi transformasi geometri.

\section{Daftar Pustaka}

Edi, S. (2021, May). Eksplorasi Konten Transformasi Geometri Berbasis Etnomatematika Pakaian Adat Suku Dayak Kenyah. In Prosiding Seminar Pendidikan Matematika dan Matematika (Vol. 3). https://doi.org/10.21831/pspmm.v3i0.137

Fitriatien, S. R. (2016). Pembelajaran berbasis etnomatematika. In Conference Paper. December

Hardiarti, S. (2017). Etnomatematika: Aplikasi Bangun Datar Segiempat pada Candi Muaro Jambi. Aksioma, 8(2), 99-110. https://doi.org/10.26877/aks.v8i2.1707

Hariastuti, R. M. (2018). Kajian Konsep-Konsep Geometris Dalam Rumah Adat Using Banyuwangi Sebagai Dasar Pengembangan Pembelajaran Kontekstual Berbasis Etnomatematika. Aksioma, 7(1), 13-21. https://doi.org/10.22487/aksioma.v7i1.177

Huda, N. T. (2018). Etnomatematika Pada Bentuk Jajanan Pasar di Daerah Istimewa Yogyakarta.
JNPM (Jurnal Nasional Pendidikan Matematika), 2(2), 217-232. http://dx.doi.org/10.33603/jnpm.v2i2.870

Kadir, A. (2013). Konsep pembelajaran kontekstual di sekolah. Dinamika Ilmu: Jurnal Pendidikan, 13(1). https://doi.org/10.21093/di.v13i1.20

Lutvaidah, U. (2016). Pengaruh metode dan pendekatan pembelajaran terhadap penguasaan konsep matematika. Formatif: Jurnal Ilmiah Pendidikan MIPA,

5(3).http://dx.doi.org/10.30998/formatif.v5i3.653

Lydiati, I. (2020). Peningkatan Koneksi Matematis Pada Materi Transformasi Geometri Menggunakan Strategi Pembelajaran React Berbantuan Media Motif Batik Kelas XI IPS 1 SMA Negeri 7 Yogyakarta. Ideguru: Jurnal Karya Ilmiah Guru, $5(1)$, 25-33. https://doi.org/10.51169/ideguru.v5i1.109

Ramdani, E. (2018). Model pembelajaran kontekstual berbasis kearifan lokal sebagai penguatan pendidikan karakter. JUPIIS: Jurnal Pendidikan Ilmu-Ilmu Sosial, 10(1), 1-10. https://doi.org/10.24114/jupiis.v10i1.8264

Yanti, D., Fauziah, A., \& Friansah, D. (2017). Pengaruh model pembelajaran kontekstual terhadap kemampuan koneksi matematika siswa kelas X SMA Negeri 4 Lubuklinggau Tahun Pelajaran 2015/2016. Jurnal Pendidikan Matematika Raflesia,

2(2). https://doi.org/10.31186/jpmr.v2i2.3698

Yanti, D., \& Haji, S. (2019). Studi Tentang KonsepKonsep Transformasi Geometri Pada Kain Besurek Bengkulu. JNPM (Jurnal Nasional Pendidikan Matematika), 3(2), 265-280. http://dx.doi.org/10.33603/jnpm.v3i2.1744 